\title{
Endometriosis and in vitro fertilisation (Review)
}

\author{
LOUKIA VASSILOPOULOU ${ }^{1}$, MICHAIL MATALLIOTAKIS ${ }^{2}$, MARIA I. ZERVOU ${ }^{3}$, CHAROULA MATALLIOTAKI $^{2}$, \\ DEMETRIOS A. SPANDIDOS ${ }^{4}$, IOANNIS MATALLIOTAKIS ${ }^{2}$ and GEORGE N. GOULIELMOS ${ }^{3}$ \\ ${ }^{1}$ Laboratory of Forensic Sciences and Toxicology, Medical School, University of Crete, Heraklion 71409; \\ ${ }^{2}$ Department of Obstetrics and Gynecology, Venizeleio and Pananio General Hospital of Heraklion, Heraklion 71409; \\ ${ }^{3}$ Section of Molecular Pathology and Human Genetics, Department of Internal Medicine, School of Medicine; \\ ${ }^{4}$ Laboratory of Clinical Virology, Medical School, University of Crete, Heraklion 71003, Crete, Greece
}

Received May 10, 2018; Accepted June 13, 2018

DOI: $10.3892 /$ etm.2018.6307

\begin{abstract}
The aim of the present review was to discuss a matter of concern in the clinical field of obstetrics/gynecology, namely the potency of in vitro fertilization (IVF) in the management of endometriosis-associated infertility. Endometriosis is a medical condition affecting one tenth of women in their fertile years, and accounts for up to 50\% of infertile women. Thus, such high prevalence has established the necessity for investigating the effectiveness of available techniques in eradicating the disease and constraining infertility as well as the accompanying pain symptoms of endometriosis. The underlying mechanisms connecting endometriosis with low fecundity have been extensively studied, both in terms of genetic alterations and epigenetic events that contribute to the manifestation of an infertility phenotype in women with the disease. Several studies have dealt with the impact of IVF in pregnancy rates (PRs) on patients with endometriosis, particularly regarding women who wish to conceive. Results retrieved from studies and meta-analyses depict a diverse pattern of IVF success, underlining the involvement of individual parameters in the configuration of the final outcome. The ultimate decision on undergoing IVF treatment should be based on objective criteria and clinicians' experience, customized according to patients' individual needs.
\end{abstract}

Correspondence to: Dr Ioannis Matalliotakis, Department of Obstetrics and Gynecology, Venizeleio and Pananio General Hospital of Heraklion, Knossos Avenue, Heraklion 71409, Crete, Greece

E-mail: matakgr@yahoo.com

Abbreviations: ART, assisted reproduction treatment; $\mathrm{COH}$, controlled ovarian hyperstimulation; DIE, deeply infiltrating endometriosis; FPT, fertility preservation technologies; ICSI, intracytoplasmic sperm injection; IUI, intrauterine insemination; $\mathrm{IVF}$, in vitro fertilization; PR, pregnancy rate(s)

Key words: endometriosis, infertility, in vitro fertilization, assisted reproduction, pregnancy rates

\section{Contents}

1. Introduction: Endometriosis as a medical condition

2. Endometriosis-associated infertility

3. Conlusion

\section{Introduction: Endometriosis as a medical condition}

Definition, etiopathogenesis and clinical picture. Endometriosis is a pathological entity characterized by the abnormal growth of endometrial tissue in ectopic sites, outside the endometrial cavity. Positions in the body where endometrial tissue can be found in the context of endometriosis include the ovaries, the rectovaginal fascia and the uterosacral ligament, the peritoneal cavity and the urinary bladder, the fallopian tubes, the colorectal tract, and even in the lungs (1). Endometrial glands and stroma can also be found in incisional scars, albeit in rare cases (2).

The frequency of endometriosis is not well defined in the general population, as available epidemiological data do not form a concrete picture. However, it is estimated that percentages rise from 2 to $10 \%$ in women belonging in the procreation age. Among infertile women, its prevalence is increased up to $50 \%$ (3). Moreover, assisted reproductive treatment is required in approximately 10 to $25 \%$ of women with endometriosis (4). The prevalence of endometriosis has been reported to be higher in women of Philippine, Indian, Japanese and Korean origin (5).

Three subcategories of endometriosis have been identified: i) superficial endometriosis (superficial peritoneal and ovarian implants); ii) ovarian endometrioma (ovarian cysts lined with endometrial mucosa) and iii) deeply infiltrating endometriosis (DIE), i.e., complex nodules consisting of endometrial, adipose and fibromuscular tissue (6). Deep infiltrating endometriosis is often multifocal, and can be roughly described as the presence of endometrial tissue that expands to a depth of more than $5 \mathrm{~mm}$ below the peritoneum. Uterine adenomyosis also exists, i.e., a benign condition characterized by presence of endometrial tissue within the myometrium.

Endometriosis is a multifactorial disease, generated by a combined action of genetic and environmental factors. Three theories are prevalent regarding the etiology of endometriosis: i) the Sampson's theory; ii) the Meyer's theory and iii) the Halban's theory. The Sampson's theory, describes that the 
retrograde blood flux, namely the transferring of endometrial cells during menstruation via the fallopian tubes to the peritoneal cavity, causes endometriosis (7). On the other hand, Halban's theory explains that endometrial cells are transferred through the lymphatic system in distal areas, while Meyer's theory supports the idea that metaplasia occurs from visceral epithelium to endometrial (8). The eutopic endometrium of patients with endometriosis has been described to differ from that of healthy individuals in terms of a molecular and cellular level (9). These variations regard hormone responsiveness, immune alteration, angiogenesis and cell proliferation. Women with endometriosis possess a resilient endometrium to some progesterone actions, affecting implantation. It has been observed that immune response to endometriosis is abnormal, namely that phagocytes and cytotoxic are incapable of eliminating the ectopic endometrial tissue. In endometriosis, the immune system ceases to be resistant to endometrial antigens and this creates a chronic inflammatory response with release of toxic products and the formation of peritoneal adhesions (10). Integrins have also been reported to play a role in endometriosis (11). Recent findings have shown that the induction of oxidative stress favors the development of ectopic endometrium (12). Vitamin D has been suggested to partake in the pathogenesis of endometriosis, as it exhibits immune-modifying, anti-inflammatory and anti-proliferative traits, although this association remain to be confirmed (13). Syndecan-4 expression has been detected in elevated concentrations in patients with endometriosis compared to women with eutopic endometrium. Thus, the upregulation of syndecan- 4 has been proposed as a pathophysiological mechanism provoking invasive cell growth (14). A genetic mechanism has also been suggested regarding the induction of endometriosis, as it has been found that the suppression of miR-183 expression favors the interception of apoptosis in endometrial cells, as well as intervenes in integrin $\beta 1$ expression (15).

Exposure to several toxicants, such as organochlorines, may also affect the progression of endometriosis, in the presence of CYP gene polymorphisms (16). Recent data showed a positive association between decreased levels of serum EPA (eicosapentaenoic acid) and the manifestation of endometriosis (17).

Particular emphasis is attributed in the information below, considering the aggregate of mechanisms linking endometriosis to infertility provocation.

The symptoms manifesting withendometriosis are dependent on the site where the ectopic endometrial tissue is identified (18). The encountered symptoms include pelvic/abdominal/ rectal pain, dysmenorrhea, dyspareunia, menorrhagia, bladder discomfort, ureteral obstruction, hematochezia, diarrhea and in case of thoracic lesions pneumothorax/hemothorax. Endometriosis presents a wide range of complications as well. It has been suggested that pregnant women with endometriosis are susceptible to developing preterm birth, antepartum hemorrhage, spontaneous hemoperitoneum (7), placental complications (19), pre-eclampsia and Caesarian section. Furthermore, endometriosis has a possible risk factor for ovarian cancer (5), albeit the causal association of endometriosis in ovarian cancer is not exhibited yet.

The American Society for Reproductive Medicine (ASMR) has provided a classification of endometriosis according to the extent of its progress. The criteria include size and depth of lesion, whether it is uni- or bilateral, ovarian intrusion and density of related adhesions. Minimal/mild disease is scored with $1-15$ points, moderate belongs to $16-40^{\circ}$, and over 40 points the disease is characterized as severe. It is important, however, to underline the fact that this scoring system has been entered into its utilization as a predictor for fertility results and it does not reflect the degree of symptoms (6).

Diagnosis and therapeutic options of endometriosis. Prompt and proper diagnosis should be the main target regarding management of endometriosis. Due to the broad range of symptoms encountered in endometriosis, a multi-disciplinary approach is often required. Laparoscopy currently is the gold-standard for the definitive diagnosis of endometriosis and histological biopsy confirms the diagnosis (20). Transvaginal ultrasound is also used for diagnostic purposes; currently, magnetic resonance has been presented as the optimal imaging tool for detecting small lesions and drawing the differentiation between benign and malignant tissue. Biomarkers for diagnosis have also been utilized, such as CA-125, although exhibiting low specificity. A new weapon in the arsenal regarding the diagnostic procedure of endometriosis has been added, in the context of molecular biomarkers, such as miRNA, the evaluation of the peritoneal fluid in terms of protein levels as well as the concertation of proinflammatory agents (21).

Therapeutic methods for endometriosis depend upon the symptoms, the patient's age and wish for childbearing, as well as the stage of disease. Medical treatment includes GnRH agonists/antagonists (e.g., deslorelin) (22), progestogens, oral contraceptives, PGs inhibitors, danazol and aromatase inhibitors. As knowledge regarding the underlying mechanisms of endometriosis improves and increases, new therapeutic options are examined. These treatments include novel NSAIDs, monoclonal antibodies, statins, antiangiogenic compounds and cannabinoids (23). Surgery is primarily indicated for pain alleviation. Considering surgical intervention, existing data suggest for minimal/mild endometriosis, the performance of laparoscopic ablation and adhesiolysis (24). Less lucid is the picture for stage III/IV endometriosis, as surgery is recommended according to ASRM. Nevertheless, an adequate number of randomized studies and meta-analyses are lacking and existing evidence is conflicting regarding pregnancy rates (PRs).

Superficial peritoneal endometriosis is an indication for laparoscopy, with subsequent ovarian stimulation \pm intrauterine insemination (IUI). Surgical operation regarding DIE for pain attenuation presents satisfying PRs either spontaneously or in the context of ART, except for the cases where the digestive tract is involved. In vitro fertilization for DIE restrain offers good results and does not favor pathological recurrence. Little evidence exists to confirm the ascendency of IVF on surgery regarding the cases of DIE-related infertility. Thus, the ultimate decision should be individualized and based on specific context. The statement that surgery could be of benefit in patients with colorectal endometriosis in terms of fertility rates is supported by other studies as well (25), with particular emphasis on laparoscopy as a more effective treatment for the achievement of spontaneous pregnancy (26).

Microscopic foci of endometrial tissue cannot be resected through surgery; thus, hormonal therapy has been suggested 
for the suppression of endometriosis and for the hindrance of its recurrence (24). However, in women with endometriosis-associated infertility, adjuvant hormonal therapy has not been suggested by the Guideline Development group (27) for the enhancement of spontaneous PR, as sufficient evidence is not available. It is noteworthy to underline that indicated is the administration of hormonal therapy to symptomatic women, in the time interval of waiting for surgical intervention or ART.

Treatment options that exist today in managing infertility associated with endometriosis include surgical intervention, as well as superovulation with IUI and IVF. Laparoscopic surgery has also been proposed as a tool for diagnosing and treating endometriosis. Especially in cases of minimal and mild endometriosis, laparoscopy has been reported to augment pregnancy rates (28). Laparoscopy, compared to open surgery, has also shown to be beneficial in the cases of colorectal endometriosis, positively affecting fertility (23). It has also been suggested as an option regarding women with severe endometriosis that have experienced repeated IVF implantation failures (29). Whether IVF is preferred over re-operation depends upon the clinical and histological picture, the patient's age and ovarian reserve. Superovulation with IUI is an effective first-line strategy for infertile women with early-stage endometriosis (30). According to ESHRE guidelines, clinicians should also consider performing laser vaporization, as enhanced spontaneous PR have been demonstrated (24). It is also known that the symptoms deriving from endometriosis can be alleviated during pregnancy (31). Therefore, pregnancy is deemed an additional therapeutic option of endometriosis.

Attention has been also given to the psychosocial dimension of patients with endometriosis, as the therapeutic approach has been proposed to take into consideration the patients' emotional wellbeing by specialists in holistic care centers (32).

\section{Endometriosis-associated infertility}

Mechanisms leading to infertility. The mechanisms inducing infertility in the context of endometriosis are orientated towards four main directions: i) mechanical obstruction due to pelvic adhesions; ii) local/systemic inflammatory processes accompanied by elevated cytokines in the peritoneal fluid; iii) altered hormonal profile and iv) genetic polymorphisms. The above suggested categorization of mechanisms is indicative, as at this point it should be mentioned that they do not comprise distinctive entities but rather demonstrate a pattern of interplay between them:

Ectopic endometrium demonstrates a similar behavior with the eutopic endometrium, which means that it can respond to hormonal stimulation by the ovaries. In distal sites, ectopic endometrium leads to pain, hemorrhage, adhesions and fibrous lesions. Local inflammation contributes to the formation of adhesions with re-triggering of inflammation, namely the onset of a vicious cycle. As ectopic endometrium may develop in any site lengthwise the reproductive tract (e.g., the Fallopian tubes), it is possible that mechanical obstruction occurs, hindering fertility (33).

Due to retrograde blood flow during menstruation in women with endometriosis, endometrial cells gain entrance in the peritoneal cavity where they interact with immune mechanisms. This initially starts through the activation of repairing mechanisms of the destroyed tissue. Macrophages, dendritic cells and mast cells release inflammation mediators responsible for vasodilation and increased endothelial permeability. Consequently, extravasation of white blood cells (neutrophils, monocytes) towards the tissue occurs. Several studies state that in endometriosis patients, elevated concentrations of macrophages, metalloproteinases, proteases, prostaglandins and cytokines can be detected in the peritoneal fluid (34,35). Cytokines include interleukins (IL)-1, -6, -7, -8, -17, -18, -33 (30), TNF- $\alpha$, VEGF, HGF, SCGF- $\beta$ (36), VCAM-1, RANTES, MCP1, SDF-1, ENA-78 and others (37). These factors create a rather hostile environment that intercepts folliculogenesis, spermatozoa transportation and transplantation (38). It has been observed that eutopic endometrium in women with endometriosis exhibits resistance towards the action of NK cells, compared to that of healthy women. A possible mechanism for this could be through the action of ICAM-1 (intracellular adhesion molecule-1) in stromal cells of the endometrium (32). Furthermore, elevated IL-6 in follicles in cases of endometriosis induces a decrease in the activation of aromatase via the MAPK signaling pathway, leading to lower conversion of androgens in estrogens and finally to reduced E2 levels.

Despite the fact that the number of macrophages in the peritoneal fluid is increased in endometriosis, these macrophages demonstrate a reduction in the expression and activation of metalloproteinase-9 (MMP-9). Moreover, CD-36 receptor exhibits a downregulation in the peritoneal macrophages, resulting in impaired phagocytic activity and decreased degradation of cellular debris that emerge due to the retrograde blood flow in menstruation occurring in endometriosis (35). In this manner, ectopic endometrial cells evade immune surveillance. Another way for achieving this is through the LFA1/ICAM-1 pathway (lymphocyte function-associated antigen-1/ICAM-1), where lymphocytes as well as NK cells are unable to identify endometrial cells.

Where pelvic endometriosis is present, macrophages become activated in the peritoneal cavity, stimulating the production of ROS, cytokines, growth factors and prostaglandins. The induced oxidative stress incites lipid hyperoxidation, whose degradation produces substances, such as malondialdehyde, which can be identified as foreign and provoke the production of antibodies. This procedure leads to destruction of red blood as well as endometrial cells found in the peritoneum, thus reinforcing this phenomenon. Through the systemic circulation, possible is the transport to the hypervascularised ovary, during the last stages of folicullogenesis, thus intervening in oocyte maturation (39). Oxidative stress may also cause lesions in mesothelial cells and further induce the presence of adhesions (40).

The elevated mRNA expression of the transcriptional factor Foxp3 has been observed. This expression is a specific surface factor for T-reg cells, which in turn play a primary role in transplantation (36).

Alterations in the peritoneal fluid in infertile patients with endometriosis can affect oocyte quality and maturation. Changes in the follicular fluid can also impact oocyte quality. The follicular fluid, produced from granular, endothelial and white cells, is a metabolically active micro-environment consisting of steroid hormones, growth factors, cytokines, 
ROS and antioxidants. ROS normally play an important role in several functions of the reproductive tract, but when they are in increased levels they exert a negative impact on E1 levels, intercepting steroidogenesis, thus hindering oocyte maturation and ovulation (41). In a previous study, where the levels of oxidative stress markers in serum and follicular fluids of patients were under ICSI, higher levels of glutathione, superoxide dismutase and 8-hydroxy-2-deoxyguanosine (8OHdG) were found, as well as elevated vitamin E concentrations. These findings suggest the presence of systemic and follicular oxidative stress in patients with endometriosis, an event that is directly linked to reduced oocyte quality and infertility (42). A complementary study showed that the follicular fluid of patients with mild endometriosis negatively affects nuclear maturation and meiotic spindle of their oocytes, thus inducing meiotic abnormalities (43).

In women with endometriosis, the hormonal profile is altered through a range of mechanisms. To begin with, the function of the pituitary-ovarian axis has been observed to be hindered, compared to healthy individuals. Specifically, the duration of the follicular phase has been referred to be extended, and abnormalities in Luteinizing hormone ( $\mathrm{LH})$ secretion motif occur as the LH surge is delayed, while biphasic LH surges may also occur (44).

In endometriosis patients, the amount of preovulatory follicles, follicular development and estradiol levels within the follicle are lower. The follicular fluid in endometriosis has been described to entail altered hormone levels, with decreased estrogen, androgen and progesterone, while activin is augmented (44).

Uterine receptivity is also affected in these patients. The expression of integrin $\alpha v \beta 3$ in endometriosis is impaired, while HOXA10, a transcription factor that stimulates $\alpha v \beta 3$ expression is reported to be decreased, with its methylation also being modified (45). The expression of other transplantation factors is also affected in endometriosis, including glycodelin A (46), osteopontin (47), leukemia inhibitory factor (48) and lysophosphatidic receptors 2 and 4 (49).

Locally/systemically affected hormonal profile consists of increased estrogen levels and estradiol receptors, as well as higher steroeidogenic factor 1 in endometrial cells. Although steroidogenic factor 1 (SF1) is present in ectopic endometrial tissue, it is not found in the eutopic endometrium. This leads to the downregulation of nearby progesterone receptors, thus overturning the hormonal balance (50). The increased amount of estradiol observed in the peritoneal fluid of patients with endometriosis increases local cyclo-oxygenase-2 (COX2) activity, resulting in stimulation of prostaglandin $\mathrm{E}$ formation, which upregulates aromatase activity, resulting in additional estradiol to perpetuate the symptoms and lesions present in endometriosis (51). There is elevated expression of both estrogen receptor $\alpha$ and estrogen receptor $\beta$ leading to a downregulation of progesterone receptors, ultimately causing the characteristic hormonal profile seen in endometriosis.

Endometriomas are related to the reduction of ovarian functionality. Various theories have been proposed regarding the decrease of the number of follicles. Hemolysis of trapped blood leads to augmentation of the Fe levels within the cyst, an event suggesting cytotoxic oxidative stress. Furthermore, primordial follicles are affected due to intense stretching of the cortex, constraining blood flow and causing ischemia. Another hypothesis is the disturbance in ovarian vascularization resulting in lower availability of gonadotropins and decreased stimulation for follicular growth (52).

A hypothesis has been stated that a relationship exists between endometriomas and diminished ovarian reserves, although not confirmed (53). Ovarian reserve reflects oocyte quantity; thus, conditions relevant to alterations in the peritoneal fluid (e.g., oxidative stress) and/or the follicular micro-environment, may affect fecundity in women with endometriosis. In cases of endometriomas, decreased levels of anti-Mullerian hormone subsequently to surgical resection are also linked to diminished ovarian reserve (54).

Notably, there is a synergy between the endocrine and immune system. Progesterone, during the secretory phase, normally displays an immune-modifying action, as it suppresses the action of $\mathrm{NF}-\kappa \mathrm{B}$, a transcriptional nuclear factor with pro-inflammatory and anti-apoptotic function. Thus, it is evident that there is a direct interaction between the endocrine and immune system. Resistance to progesterone can be effectuated by genetic polymorphisms, alterations in microRNA expression and epigenetic modifications (exposure to toxins, resistance to retinoids). It has been stated that the enhanced progesterone signal forms a pro-inflammatory phenotype, while chronic inflammation induces progesterone resistance, underlying this bidirectional relationship (55).

Altered genetic expression and genetic polymorphisms also represent suggested mechanisms of endometriosis manifestation. As previously mentioned, genes responsible for the expression of pro-inflammatory cytokines and adhesion molecules are expressed at an augmented rate, including CXCL1, CX3CL1, CXCL9, CXCL10,IL-32, CXCR2, IL-7R, $I C A M-1$ and $S E L L$, respectively (56). It has also been observed that a reduced expression of $\mathrm{NOTCH} 1$ and $\mathrm{NOTCH} 2$ induces disruption in this signal pathway, affecting endometrium decidualization (36). Apart from previous gene-association studies, recent genome-wide association studies (GWAS) have identified 14 chromosomal regions as genetic risk factors for endometriosis thus far (57). Furthermore, whole exome sequencing (WES) is currently used extensively to detect rare causative gene mutations leading to endometriosis. In total, around 90 genes have been identified to present impaired expression in the eutopic endometrium of infertile women suffering from endometriosis. Oxidative stress in the peritoneal and follicular fluid, as well as epigenetic alterations in regional areas, either via DNA methylation or through histone modifications (58), and the expression of $C Y P 19 A 1$ in cumulus cells has been reported to be decreased $(59,60)$.

Various studies have described an association between gene polymorphisms and low fecundity in women with endometriosis. Genetic polymorphisms that have been reported to confirm this assumption include: i) ESR1 rs9340799 SNP and ESR2 (CA) n repeats polymorphism were suggested to contribute to a phenotype of infertility in endometriosis patients $(61,62)$; ii) G-765C polymorphism in promoter region of $C O X-2$ gene, particularly linked to endometriosis stages III and IV-related infertility (63); iii) rs16826658 and rs3820280 polymorphisms in WNT4 gene (64); iv) rs7582694 single nucleotide polymorphism of STAT4 gene (65); v) HSD17B1 937G polymorphism, described as a risk factor for endometriosis 
stages I and II (66); vi) Polymorphism in FCL3_3, reported to increase possibility for infertility in patients, independently of the disease stage (67) and vii) $460 \mathrm{~T} / 405 \mathrm{C}$ haplotype in the $V E G F$ gene, associated with lower promoter activity, has a lower frequency in women with endometriosis (68).

In vitro fertilization technique and endometriosis. As aforementioned, infertility is a problem that many patients with endometriosis encounter. Often, in the moiety of patients with developed endometriosis, and despite the various treatment options, disease-induced infertility does not constitute a priority.

General methods of achieving infertility management include surgical operation (laparoscopically or open surgery), ovulation stimulation \pm IUI and ART. Fertility preservation technologies also include oocytic/embryonic freezing and ovarian tissue cryopreservation (69). In general, controlled ovarian hyperstimulation $(\mathrm{COH})$, oocyte retrieval, IVF and embryo cryopreservation are the most established techniques. $\mathrm{COH}$ as an infertility-hindering technique contributes to the development of follicles and importantly increases estradiol plasma levels. Endometriosis is dependent on estrogens and the number of ovulatory events has been reported to play an important role in the formation of ovarian endometriomas. Factors that exert a positive effect in the success of IVF include young age, history of previous livebirth/pregnancy, short duration of infertility and infertility attributed to unknown factors but nevertheless presenting good prognostic potential (70).

An inquiry that emerges at this point is whether IVF should be preferred as a first-line treatment or as a resort. Clear IVF indications consist of infertility due to tubal bilaterality, advanced endometriosis stage that has led to tubal dysfunction, menopausal state requiring egg donation, preimplantation screening for genetically inherited pathologies and in case of severe male factor infertility (i.e., pathological spermogram) (27,71,72). In addition to those, IVF/ICSI represent the gold standard in the cases of severe male contribution to decreased fecundity. Hydrosalpinges stage $\geq 2$ have been associated with low PR even after surgery; thus, IVF herein is a promising solution. It has been suggested that in women less than 35 years of age, there is a margin of a one-year waiting period postoperatively until they undergo IVF, while women older than 35 year should undergo surgery earlier, in a time interval of 6 months postoperatively. As far as the ovarian stimulation is concerned, administration of $\mathrm{GnRH}$ agonists/antagonists in women with healthy ovarian reserve is recommended (73).

By contrast, certain conditions exist, where IVF is not deemed a primary infertility management method. These conditions are unexplained infertility, endometriosis without tubal disease, unilateral tubal obstruction, diminished ovarian reserve and mild male infertility factor.

The argument regarding this issue concern the invasiveness that characterizes the IVF techniques, the clinician's personal adjustment and opinion, and the elevated costs required. In addition to these parameters, IVF exhibits certain complications: ovarian hyperstimulation syndrome, thromboembolic episodes, ectopic pregnancies, ovarian torsion and complications deriving from egg retrieval. For the above main reasons, it can be deduced that IVF in endometriosis plays a controversial role, not only by objective hindrances but also due to conflicting results that have been retrieved thus far from the existing literature.

To begin with, several studies have demonstrated the positive effect of IVF in the elimination of endometriosisassociated infertility, especially in women of procreation age. Thus, it has been proposed by Fadhlaoui et al (24) that, in patients with stage I/II endometriosis, IVF in combination with controlled ovarian stimulation (COS) may prove to be beneficial for PR increase. It is though unclear as to whether surgery for stage I/II prior to COS/IVF could further improve PR. That study also showed that medication for treatment purposes did not seem to improve spontaneous PR. Those findings are in agreement with Leung et al (74), where recommendation regarding minimal/mild endometriosis is the ovulation stimulation along with letrozole/clomiphene citrate administration for the enhancement of PR. It has been mentioned that the outcome of surgical intervention is enhanced when accompanied by IVF, particularly for pain relief and a diagnosis in ambivalent cases should be confirmed (6). However, according to Capelle et al (75), in the cases of DIE, surgery does not seem to improve PR prior to IVF. It is recommended that women with endometriosis stages II, III and IV should undergo treatment with one, two and three doses of GnRH-a depot, in order to improve IVF outcome after laparoscopy (76). A prospective multicenter study performed by Ballester et al (77), identified that intracytoplasmic sperm injection-IVF leads to an elevated cumulative pregnancy rate per patient in women with colorectal endometriosis, though factors including the presence of adenomyosis, levels of anti-Mullerian hormone in the serum and age, affect the final outcome. Serum anti-Mullerian hormone in particular can play a predictive role for ovarian responsiveness in women with endometriosis (78). According to a meta-analysis performed by Yang et al (79), it is underlined that ovarian responsiveness to stimulation did not present a significant statistical difference between women with endometriomas and control group. The efficiency of assisted reproductive technologies subsequently to colorectal surgical intervention has been underlined four years later by Ballester et al (80), in patients with endometriosis-induced infertility.

It has been stated that PR is improved when patients undergo surgery prior to IVF particularly in the early stages of endometriosis. PR are also enhanced if GnRH agonists are administered prior to IVF. Postoperative medical treatment does not seem to incite a rise in PR, in women aiming at spontaneous conception, while they also add an unwanted time delay $(30,81)$. Opøien et al (82), have underlined the important role of surgery in eradicating macroscopic lesions. In the present study, it has been found that women belonging to stage I/II and undergoing IVF/ICSI had shorter time to pregnancy and achieved live-birth at higher rates. Mavrelos and Saridogan suggested surgery and subsequently a time interval prior to superovulation \pm IUI in young women with I/II stage and good ovarian reserve as well as in women with less than $3 \mathrm{~cm}$ unilateral endometriomas (83). Considering older women with low ovarian reserve, it has been suggested that surgery may not be that beneficial, except for the cases where bulky lesions intercept access to the ovaries. Similarly Rizk et al (84), support the view that women of stage I/II should undergo surgical excision/ ablation of endometriosis as first 
option, as it increases PR up to double. Indeed, according to Garcia-Velasco et al (4), the need for IVF is described as imperative; not only for time saving and economic sparing, but also for the constraint of unwanted surgery complications. It is also postulated that surgery should be considered only in cases of large lesions, malignancy and pain. Furthermore Dechanet et al (85), agree upon the combination of surgery and ART, targeting at increasing PR. Gn-RH agonists have been also reported to contribute in PR elevation, compared to GnRH antagonist (86).

A considerable number of studies have exhibited an independent association between IVF efficacy and endometriosis-related infertility. In addition, IVF has provided results in retrospective cohort studies independently of the main infertility factor, thus indicating promising results in endometriosis management (as it is revealed that endometriosis does not affect IVF outcome). Indeed, IVF has been described to be irrelevant to the state of endometriosis, or even additional infertility factors $(87,88)$. Moreover, IVF potential has been described to be as effective as in women with any other cause of infertility (89). In accordance to that, further studies have drawn similar conclusions; in a systematic review and metaanalysis of retrospective and randomized control-trial studies, IVF/ICSI seems to demonstrate results independently of the cause of low fecundity. In that same study, it was identified that surgery for endometriosis does not affect IVF outcomes (90). Similarly, patients with endometriosis demonstrate comparable results regarding successful IVF rates, as with women with infertility due to tubal factors, irrelevant of endometriosisinduced lesions $(91,92)$. The same study also stated that prior to IVF, and for the enhancement of successful IVF rates, aggressive $\mathrm{COH}$, medical suppression of the pituitary gland (93) and surgical intervention are recommended. IVF has also been reported by several authors to not contribute to disease progression. Crochet et al, performed a retrospective case-control study, with the aim of investigating the progression of endometriosis after IVF treatment in women having previously undergone surgical intervention (94). The findings suggested that a non-important deviation was found in the results of the patients belonging to the IVF administration group compared to controls, further indicating that IVF is not responsible for aggravation of endometriosis (44). This statement agrees with the findings of Benaglia et al (95), as well as with the that PR in IVF are inversely linked with the severity of endometriosis (96). Particularly for $\mathrm{COH}$, it has been displayed that PR, oocytes and embryonic functionality are not affected by the presence of endometrioma or in operation for that reason (97). IVF pregnancy rate has been demonstrated to be negatively associated with disease severity, with the optimal time for IVF performance being 7-25 months subsequently to surgical intervention, according to previous findings (98). Ovarian reserve status also seems not to affect the progression of endometriosis in patients who undergo IVF (99). Regarding risk of miscarriage when endometriosis is present, IVF seems to be an independent factor (100). In addition, the chance of women with endometriosis to conceive are similar to disease-free women, as identified in a previous study (101). It has been stated that women with endometriosis undergoing IVF exhibit aneuploidy percentages similar to healthy women of the IVF treatment group (102).
Attention should be also paid to the endometriosis fertility index (EFI), as it comprises a novel staging system and proves to be a useful tool in clinicians' hands (103). The EFI is used for the prediction of fertility subsequently to surgery. It is proposed that EFI presents better value in the estimation of IVF outcome, in comparison to r-AFS classification (104). Considering women that have undergone surgery, a subsequent estimation of EFI $\geq 5-12$ months postoperatively, indicated is the implementation of IVF-ET (105). For the estimation of cumulative birth rates following IVF, competing risk has been used as a tool for evaluation (106).

Another issue occupying clinicians is the effect of IVF on pain symptoms. It has been shown by a recent study that IVF does not intensify endometriosis-related pain (15). In general, few data exist that give an indication on addressing this topic, as the impact of endometriosis on pregnancy is ambiguous.

However, several published studies describe a negative association between endometriosis and IVF outcome. Coccia et al (107) determined that the success rate of IVF is inversely correlated with endometriosis stage III/IV. This negative association has also been exhibited by Cohen et al (108), with the additional suggestion of GnRH administration prior to IVF for improving the final outcome. The limited effectiveness of IVF in endometriosis has been supported by other authors as well. Pallacks et al (109), state that endometriosis reduces the chance of conceiving, even after IVF/ICSI. Surgery for endometriomas alone does not enhance IVF, according to Polat et al (110). IVF can be effective under certain circumstances, which include the administration of GnRH and letrozole for the achievement of elevated PR. Weak outcomes from IVF even after surgery have also been reported by other studies $(111,112)$. Cohen et al (108), performed a retrospective study by evaluating the results of IVF/ICSI cycle in young women with low ovarian reserve. It was found that these women presented decreased birth rates following an IVF/ICSI cycle and that elevated gonadotropin dose of onset could possibly be related to improved results.

Endometriosis is a frequently encountered pathology affecting women of reproductive age. Its symptomatology and complications impel clinical doctors to implement appropriate corrective or mitigating techniques, for pain alleviation and fecundity enhancement. Among them, IVF possesses a neuralgic place in the therapeutic arsenal. Previous studies have suggest the beneficial role of IVF in intercepting endometriosis-associated infertility, displaying an efficacy even equivalent to disease-free women. Nonetheless, a number of studies have identified a negative impact of IVF on PR augmentation. The vast majority of studies, however, agree upon the fact that individual patient factors play the most crucial role in the final outcome. Treatment choice depends upon patient's age, duration of infertility, disease level of progression and wish for childbearing.

Therefore, it can be deduced that the management of endometriosis-related infertility remains a matter of dispute. Thus, clinicians are advised to make an insightful decision for the optimal result, adjusting appropriately their scientific knowledge and experience in congruence with patients' individual needs. 


\section{Acknowledgements}

Not applicable.

\section{Funding}

No funding was received.

\section{Availability of data and materials}

All data generated or analyzed during this study are included in this published article.

\section{Authors' contributions}

LV and MM conceived and designed the study. LV, MM, MIZ and $\mathrm{CM}$ researched the literature, performed analysis of data and drafted the manuscript. GNG drafted the manuscript. GNG, DAS and IM critically revised the article for important intellectual content.

\section{Ethics approval and consent to participate}

Not applicable.

\section{Consent for publication}

Not applicable.

\section{Competing interests}

Demetrios A. Spandidos is the Editor-in-Chief for the journal, but had no personal involvement in the reviewing process, or any influence in terms of adjudicating on the final decision, for this article.

\section{References}

1. Nair SS and Nayar J: Thoracic endometriosis syndrome: A veritable pandora's box. J Clin Diagn Res 10: QR04-QR08, 2016.

2. Miccini M, Gregori M, Ferraro D, Ciardi A, Cassibba S and Biacchi D: Abdominal scar endometriosis: Case report. Clin Exp Obstet Gynecol 43: 431-433, 2016.

3. Eisenberg VH, Weil C, Chodick G and Shalev V: Epidemiology of endometriosis: A large population-based database study from a healthcare provider with 2 million members. BJOG 125: 55-62, 2018.

4. Garcia-Velasco JA and Somigliana E: Management of endometriomas in women requiring IVF: To touch or not to touch. Hum Reprod 24: 496-501, 2009.

5. Yamamoto A, Johnstone EB, Bloom MS, Huddleston HG and Fujimoto VY: A higher prevalence of endometriosis among Asian women does not contribute to poorer IVF outcomes. J Assist Reprod Genet 34: 765-774, 2017.

6. Carpinello OJ, Sundheimer LW, Alford CE, Taylor RN and DeCherney AH: Endometriosis. In: Endotext. De Groot LJ, Chrousos G, Dungan K, et al (eds). http://www.endotext.org/. Accessed: ?

7. Leyland N, Casper R, Laberge P, Singh SS, Allen L, Arendas K, Leyland N, Allaire C, Awadalla A, Best C, et al: SOGC: Endometriosis: Diagnosis and management. J Obstet Gynaecol Can 32 (Suppl 2): S1-S32, 2010.

8. van der Linden P: Theories on the pathogenesis of endometriosis. Hum Reprod 11: 53-65, 1996.

9. Brosens I, Brosens JJ and Benagiano G: The eutopic endometrium in endometriosis: Are the changes of clinical significance? Reprod Biomed Online 24: 496-502, 2012.
10. Capobianco A, Cottone L, Monno A, Manfredi AA and RovereQuerini P: The peritoneum: healing, immunity and diseases. J Pathol 243: 137-147, 2017.

11. Aznaurova YB, Zhumataev MB, Roberts TK, Aliper AM and Zhavoronkov AA: Molecular aspects of development and regulation of endometriosis. Reprod Biol Endocrinol 12: 50, 2014.

12. Harlev A, Gupta S and Agarwal A: Targeting oxidative stress to treat endometriosis. Expert Opin Ther Targets 19: 1447-1464, 2015.

13. Buggio L, Somigliana E, Pizzi MN, Dridi D, Roncella E and Vercellini P: 25-hydroxyvitamin D serum levels and endometriosis: Results of a case-control study. Reprod Sci: Jan 1, 2018 (Epub ahead of print)..

14. Chelariu-Raicu A, Wilke C, Brand M, Starzinski-Powitz A, Kiesel L, Schüring AN and Götte M: Syndecan-4 expression is upregulated in endometriosis and contributes to an invasive phenotype. Fertil Steril 106: 378-385, 2016.

15. Chen J, Gu L, Ni J, Hu P, Hu K and Shi YL: MIR-183 regulates ITGB1P expression and promotes invasion of endometrial stromal cells. Biomed Res Int: doi: 10.1155/2015/340218.

16. Docea AO, Vassilopoulou L, Fragou D, Arsene AL, Fenga C Kovatsi L, Petrakis D, Rakitskii VN, Nosyrev AE, Izotov BN, et al: CYP polymorphisms and pathological conditions related to chronic exposure to organochlorine pesticides. Toxicol Rep 4: 335-341, 2017.

17. Hopeman MM, Riley JK, Frolova AI, Jiang H and Jungheim ES: Serum polyunsaturated fatty acids and endometriosis. Reprod Sci 22: 1083-1087, 2015.

18. Borghese B, Santulli P, Marcellin L and Chapron C: Definition, description, clinicopathological features, pathogenesis and natural history of endometriosis: CNGOF-HAS Endometriosis Guidelines. Gynécol Obstét Fertil Sénol 46: 156-167, 2018.

19. Benaglia L, Candotti G, Papaleo E, Pagliardini L, Leonardi M, Reschini M, Quaranta L, Munaretto M, Viganò P, Candiani M, et al: Pregnancy outcome in women with endometriosis achieving pregnancy with IVF. Hum Reprod 31: 2730-2736, 2016.

20. Giudice LC and Kao LC: Endometriosis. Lancet 364: 1789-1799, 2004.

21. Domínguez F: Search for new molecular biomarkers to diagnose endometriosis continues. Fertil Steril 109: 615-616, 2018.

22. Agarwal SK, Daniels A, Drosman SR, Udoff L, Foster WG, Pike MC, Spicer DV and Daniels JR: Treatment of endometriosis with the GnRHa deslorelin and add-back estradiol and supplementary testosterone. BioMed Res Int 2015: 934164, 2015.

23. Clemenza S, Sorbi F, Noci I, Capezzuoli T, Turrini I, Carriero C Buffi N, Fambrini M and Petraglia F: From pathogenesis to clinical practice: Emerging medical treatments for endometriosis. Best Pract Res Clin Obstet Gynaecol: doi: 10.1016/ j.bpobgyn.2018.01.021.

24. Fadhlaoui A, Bouquet de la Jolinière J and Feki A: Endometriosis and infertility: How and when to treat? Front Surg 1: 24, 2014.

25. Daraï E, Cohen J and Ballester M: Colorectal endometriosis and fertility. Eur J Obstet Gynecol Reprod Biol 209: 86-94, 2017.

26. Daraï E, Lesieur B, Dubernard G, Rouzier R, Bazot M and Ballester M: Fertility after colorectal resection for endometriosis: Results of a prospective study comparing laparoscopy with open surgery. Fertil Steril 95: 1903-1908, 2011.

27. Dunselman GAJ, Vermeulen N, Becker C, Calhaz-Jorge C, D'Hooghe T, De Bie B, Heikinheimo O, Horne AW, Kiesel L, Nap A, et al: European society of human reproduction and embryology: ESHRE guideline: Management of women with endometriosis. Hum Reprod 29: 400-412, 2014.

28. Duffy JMN, Arambage K, Correa FJS, Olive D, Farquhar C, Garry R, Barlow DH and Jacobson TZ: Laparoscopic surgery for endometriosis. Cochrane Collab: doi: 10.1002/14651858. CD011031.pub2.

29. Soriano D, Adler I, Bouaziz J, Zolti M, Eisenberg VH, Goldenberg M, Seidman DS and Elizur SE: Fertility outcome of laparoscopic treatment in patients with severe endometriosis and repeated in vitro fertilization failures. Fertil Steril 106: 1264-1269, 2016.

30. Bernardi LA and Pavone ME: Endometriosis: An update on management. Wom Health Lond 9: 233-250, 2013.

31. Brosens IA, Lier MC, Mijatovic V, Habiba M and Benagiano G: Severe spontaneous hemoperitoneum in pregnancy may be linked to in vitro fertilization in patients with endometriosis: A systematic review. Fertil Steril 106: 692-703, 2016.

32. Aerts L, Grangier L, Streuli I, Dällenbach P, Marci R, Wenger JM and Pluchino N: Psychosocial impact of endometriosis: From co-morbidity to intervention. Best Pract Res Clin Obstet Gynaecol: doi: 10.1016/j.bpobgyn.2018.01.008. 
33. Wu MH, Hsiao KY and Tsai SJ: Endometriosis and possible inflammation markers. Gynecol Minim Invasive Ther 4: 61-67, 2015.

34. Jørgensen H, Hill AS, Beste MT, Kumar MP, Chiswick E, Fedorcsak P, Isaacson KB, Lauffenburger DA, Griffith LG and Qvigstad E: Peritoneal fluid cytokines related to endometriosis in patients evaluated for infertility. Fertil Steril 107: 1191-1199, e2, 2017.

35. Herington JL, Bruner-Tran KL, Lucas JA and Osteen KG: Immune interactions in endometriosis. Expert Rev Clin Immunol 7: 611-626, 2011.

36. Miller JE, Ahn SH, Monsanto SP, Khalaj K, Koti M and Tayade C: Implications of immune dysfunction on endometriosis associated infertility. Oncotarget 8: 7138-7147, 2017.

37. Haydardedeoglu B and Zeyneloglu HB: The impact of endometriosis on fertility. Wom Health Lond 11: 619-623, 2015.

38. Evans MB and Decherney AH: Fertility and endometriosis. Clin Obstet Gynecol 60: 497-502, 2017.

39. Da Broi MG, Jordao-Jr A, Ferriani R and Navarro P: Oocyte oxidative DNA damage may be involved in minimal/mild endometriosis-related infertility. Mol Reprod Dev 85: 1-29, 2017.

40. Da Broi MG and Navarro PA: Oxidative stress and oocyte quality: Ethiopathogenic mechanisms of minimal/mild endometriosisrelated infertility. Cell Tissue Res 364: 1-7, 2015.

41. Augoulea A,Mastorakos G,LambrinoudakiI,Christodoulakos G and Creatsas G: The role of the oxidative-stress in the endometriosis-related infertility. Gynecol Endocrinol 25: 75-81, 2009.

42. Da Broi MG, Albuquerque FO, de Andrade AZ, Cardoso RL, Jordão Jr AA and Navarro PA: Systemic and follicular oxidative stress in infertile women with endometriosis undergoing controlled ovarian stimulation for ICSI: Is there a role in the etiopathogenesis of infertility? Fertil Steril 102: e79, 2014.

43. Da Broi MG, Malvezzi H, Paz CCP, Ferriani RA and Navarro PA Follicular fluid from infertile women with mild endometriosis may compromise the meiotic spindles of bovine metaphase II oocytes. Hum Reprod 29: 315-323, 2014.

44. Stilley JAW, Birt JA and Sharpe-Timms KL: Cellular and molecular basis for endometriosis-associated infertility. Cell Tissue Res 349: 849-862, 2012

45. Donaghay M and Lessey BA: Uterine receptivity: Alterations associated with benign gynecological disease. Semin Reprod Med 25: 461-475, 2007.

46. Focarelli R, Luddi A, De Leo V, Capaldo A, Stendardi A, Pavone V, Benincasa L, Belmonte G, Petraglia F and Piomboni P: Dysregulation of GdA expression in endometrium of women with endometriosis: Implication for endometrial receptivity. Reprod Sci 25: 579-586, 2018

47. Casals G, Ordi J, Creus M, Fábregues F, Carmona F, Casamitjana R and Balasch J: Expression pattern of osteopontin and $\alpha v \beta 3$ integrin during the implantation window in infertile patients with early stages of endometriosis. Hum Reprod 27: $805-813,2012$.

48. Alizadeh Z, Shokrzadeh N, Saidijam M and Sanoee MF: Semi-quantitative analysis of HOXA11, leukemia inhibitory factor and basic transcriptional element binding protein $1 \mathrm{mRNA}$ expression in the mid-secretory endometrium of patients with endometriosis. Iran Biomed J 15: 66-72, 2011.

49. Kowalczyk-Zieba I, Woclawek-Potocka I, Wasniewski T, Boruszewska D, Grycmacher K, Sinderewicz E, Staszkiewicz J and Wolczynski S: LPAR2 and LPAR4 are the main receptors responsible for LPA actions in ovarian endometriotic cysts. Reprod Sci: doi: 10.1177/1933719118766263.

50. Vasquez YM, Wu S-P, Anderson ML, et al: Endometrial expression of steroidogenic factor 1 promotes cystic glandular morphogenesis. Mol Endocrinol 30: 518-532, 2016.

51. Olivares C, Bilotas M, Buquet R, Borghi M, Sueldo C, Tesone M and Meresman G: Effects of a selective cyclooxygenase-2 inhibitor on endometrial epithelial cells from patients with endometriosis. Hum Reprod 23: 2701-2708, 2008.

52. Berlanda N, Alberico D, Barbara G, Frattaruolo MP and Vercellini P: Exploring the relationship between endometriomas and infertility. Wom Health Lond 11: 127-135, 2015.

53. Benaglia L, Castiglioni M, Paffoni A, Sarais V, Vercellini P and Somigliana E: Is endometrioma-associated damage to ovarian reserve progressive? Insights from IVF cycles. Eur J Obstet Gynecol Reprod Biol 217: 101-105, 2017.

54. Pankhurst MW: A putative role for anti-Müllerian hormone (AMH) in optimising ovarian reserve expenditure. J Endocrinol 233: R1-R13, 2017.
55. Patel BG, Lenk EE, Lebovic DI, Shu Y, Yu J and Taylor RN: Pathogenesis of endometriosis: Interaction between endocrine and inflammatory pathways. Best Pract Res Clin Obstet Gynaecol: doi: 10.1016/j.bpobgyn.2018.01.006.

56. Ahn SH, Khalaj K, Young SL, Lessey BA, Koti M and Tayade C: Immune-inflammation gene signatures in endometriosis patients. Fertil Steril 106: 1420-1431.e7, 2016.

57. Sapkota Y, Steinthorsdottir V, Morris AP, Fassbender A, Rahmioglu N, De Vivo I, Buring JE, Zhang F, Edwards TL, Jones S, et al: Meta-analysis identifies five novel loci associated with endometriosis highlighting key genes involved in hormone metabolism. Nat Commun 8: doi: 10.1038/ncomms15539.

58. Menezo YJR, Silvestris E, Dale B and Elder K: Oxidative stress and alterations in DNA methylation: Two sides of the same coin in reproduction. Reprod Biomed Online 33: 668-683, 2016.

59. Barcelos IDES, Donabella FC, Ribas CP, Meola J, Ferriani RA, de Paz CCP and Navarro PA: Down-regulation of the CYP19A1 gene in cumulus cells of infertile women with endometriosis. Reprod Biomed Online 30: 532-541, 2015.

60. Hosseini E, Mehraein F, Shahhoseini M, Karimian L, Nikmard F, Ashrafi M, Afsharian P and Aflatoonian R: Epigenetic alterations of CYP19A1 gene in Cumulus cells and its relevance to infertility in endometriosis. J Assist Reprod Genet 33: 1105-1113, 2016.

61. Paskulin DD, Cunha-Filho JS, Paskulin LD, Souza CAB and Ashton-Prolla P: ESR1 rs9340799 is associated with endometriosis-related infertility and in vitro fertilization failure. Dis Markers 35: 907-913, 2013.

62. Lamp M, Peters M, Reinmaa E, Haller-Kikkatalo K, Kaart T, KadastikU,Karro H,Metspalu A and Salumets A: Polymorphisms in ESR1, ESR2 and HSD17B1 genes are associated with fertility status in endometriosis. Gynecol Endocrinol 27: 425-433, 2011.

63. Cavalcanti V, Ponce TG, Mafra FA, André GM, Christofolini DM, Barbosa CP and Bianco B: Evaluation of the frequency of G-765C polymorphism in the promoter region of the COX-2 gene and its correlation with the expression of this gene in the endometrium of women with endometriosis. Arch Gynecol Obstet 293: 109-115, 2016.

64. Mafra F, Catto M, Bianco B, Barbosa CP and Christofolini D: Association of WNT4 polymorphisms with endometriosis in infertile patients. J Assist Reprod Genet32: 1359-1364, 2015.

65. Zamani MR, Salmaninejad A, Akbari Asbagh F, Masoud A and Rezaei N: STAT4 single nucleotide gene polymorphisms and susceptibility to endometriosis-related infertility. Eur J Obstet Gynecol Reprod Biol 203: 20-24, 2016.

66. Osiński M, Mostowska A, Wirstlein P, Skrzypczak J, Jagodziński PP and Szczepańska M: Involvement of 17ß-hydroxysteroid dehydrogenase type gene $1937 \mathrm{~A}>\mathrm{G}$ polymorphism in infertility in Polish Caucasian women with endometriosis. J Assist Reprod Genet 34: 789-794, 2017.

67. Zhang $\mathrm{H}$, Zhang Z, Li G, Wang S, Zhang S and Xie B: Association of FCRL3 genetic polymorphisms with endometriosis-related infertility risk: An independent study in Han Chinese. Medicine (Baltimore) 94: e1168, 2015.

68. Bhanoori M, Babu KA, Deenadayal M, Kennedy S and Shivaji S: The interleukin-6-174G/C promoter polymorphism is not associated with endometriosis in South Indian women. J Soc Gynecol Investig 12: 365-369, 2005.

69. Carrillo L, Seidman DS, Cittadini E and Meirow D: The role of fertility preservation in patients with endometriosis. J Assist Reprod Genet 33: 317-323, 2016.

70. Papathanasiou A and Bhattacharya S: Prognostic factors for IVF success: Diagnostic testing and evidence-based interventions. Semin Reprod Med 33: 65-76, 2015.

71. Huang LN, Tan J, Hitkari J and Dahan MH: Should IVF be used as first-line treatment or as a last resort? A debate presented at the 2013 Canadian Fertility and Andrology Society meeting. Reprod Biomed Online 30: 128-136, 2015.

72. Cohen J, Mathieu d'Argent E, Selleret L, Antoine JM, Chabbert-Buffet N, Bendifallah S, Ballester M and Darai E: Fertility and deep infiltrating endometriosis. Presse Med 46: 1184-1191, 2017.

73. Barri PN, Coroleu B, Tur R, Barri-Soldevila PN and Rodríguez I: Endometriosis-associated infertility: Surgery and IVF, a comprehensive therapeutic approach. Reprod Biomed Online 21: 179-185, 2010.

74. Leung AS and Dahan MH: The benefits of other treatments than in vitro fertilization to aid conception in minimal and mild endometriosis. Minerva Ginecol 68: 675-686, 2016.

75. Capelle A, Lepage J, Langlois C, Lefebvre C, Dewailly D, Collinet P and Rubod C: Surgery for deep infiltrating endometriosis before in vitro fertilization: No benefit for fertility? Gynécol Obstét Fertil 43: 109-116, 2015. 
76. Prasad S, Bassi R, Kumar Y, Kumar A and Prasad S: Treatment options of endometriosis prior to in vitro fertilization/intracytoplasmic sperm injection cycles to improve conception rate Taiwan J Obstet Gynecol 54: 316-318, 2015.

77. Ballester M, d'Argent EM, Morcel K, Belaisch-Allart J, Nisolle M and Daraï E: Cumulative pregnancy rate after ICSI-IVF in patients with colorectal endometriosis: Results of a multicentre study. Hum Reprod 27: 1043-1049, 2012.

78. Yoo JH, Cha SH, Park CW, Kim JY, Yang KM, Song IO, Koong MK, Kang IS and Kim HO: Serum anti-Müllerian hormone is a better predictor of ovarian response than FSH and age in IVF patients with endometriosis. Clin Exp Reprod Med 38: 222-227, 2011

79. Yang C, Geng Y, Li Y, Chen C and Gao Y: Impact of ovarian endometrioma on ovarian responsiveness and IVF: A systematic review and meta-analysis. Reprod Biomed Online 31: 9-19, 2015

80. Ballester M, Roman H, Mathieu E, Touleimat S, Belghiti J and Dara1 E: Prior colorectal surgery for endometriosis-associated infertility improves ICSI-IVF outcomes: Results from two expert centres. Eur J Obstet Gynecol Reprod Biol 209: 95-99, 2017.

81. Decleer W, Osmanagaoglu K, Verschueren K, Comhaire F and Devroey P: RCT to evaluate the influence of adjuvant medical treatment of peritoneal endometriosis on the outcome of IVF Hum Reprod 31: 2017-2023, 2016.

82. Opøien HK, Fedorcsak P, Byholm T and Tanbo T: Complete surgical removal of minimal and mild endometriosis improves outcome of subsequent IVF/ICSI treatment. Reprod Biomed Online 23: 389-395, 2011

83. Mavrelos D and Saridogan E: Treatment of endometriosis in women desiring fertility. J Obstet Gynecol India 65: 11-16, 2015.

84. Rizk B, Turki R, Lotfy H, Ranganathan S, Zahed H, Freeman AR, Shilbayeh Z, Sassy M, Shalaby M and Malik R: Surgery for endometriosis-associated infertility: Do we exaggerate the magnitude of effect? Facts Views Vis Obgyn 7: 109-118, 2015

85. Dechanet C, Rihaoui S, Reyftmann L, Hedon B, Hamamah S and Dechaud H: Endometriosis and fertility: Results after surgery and Assisted Reproductive Technology (ART). Gynécol Obstét Fertil 39: 3-7, 2011.

86. Kolanska K, Cohen J, Bendifallah S, Selleret L, Antoine JM, Chabbert-Buffet N, Darai E and d'Argent EM: Pregnancy outcomes after controlled ovarian hyperstimulation in women with endometriosis-associated infertility: $\mathrm{GnRH}$-agonist versus GnRH-antagonist. J Gynecol Obstet Hum Reprod 46: 681-686, 2017.

87. Dmowski WP, Rana N, Michalowska J, Friberg J, Papierniak C and el-Roeiy A: The effect of endometriosis, its stage and activity, and of autoantibodies on in vitro fertilization and embryo transfer success rates. Fertil Steril 63: 555-562, 1995

88. González-Comadran M, Schwarze JE, Zegers-Hochschild F, Souza MCB, Carreras R and Checa MÁ: The impact of endometriosis on the outcome of Assisted Reproductive Technology. Reprod Biol Endocrinol 15: 1-7, 2017.

89. Pop-Trajkovic S, Kopitovic V, Popovic J, Antic V, Radovic D and Zivadinovic R: In vitro fertilization outcome in women with endometriosis and previous ovarian surgery. Indian J Med Res 140: 387-391, 2014.

90. Hamdan M, Dunselman G, Li TC and Cheong Y: The impact of endometrioma on IVF/ICSI outcomes: A systematic review and meta-analysis. Hum Reprod Update 21: 809-825, 2015.

91. Dong X, Liao X, Wang R and Zhang H: The impact of endometriosis on IVF/ICSI outcomes. Int J Clin Exp Pathol 6: 1911-1918, 2013.

92. Barbosa MAP, Teixeira DM, Navarro PAAS, Ferriani RA, Nastri CO and Martins WP: Impact of endometriosis and its staging on assisted reproduction outcome: Systematic review and meta-analysis. Ultrasound Obstet Gynecol 44: 261-278, 2014.

93. van der Houwen LEE, Mijatovic V, Leemhuis E, Schats R, Heymans MW, Lambalk CB and Hompes PG: Efficacy and safety of IVF/ICSI in patients with severe endometriosis after long-term pituitary down-regulation. Reprod Biomed Online 28: 39-46, 2014.

94. Crochet P, Lathi R, Dahan M, Ocampo J, Nutis M and Nezhat C: Control-matched surgical evaluation of endometriosis progression after IVF: a retrospective cohort study. Minerva Ginecol 68 : 481-486, 2016.
95. Benaglia L, Somigliana E, Santi G, Scarduelli C, Ragni G and Fedele L: IVF and endometriosis-related symptom progression: Insights from a prospective study. Hum Reprod 26: 2368-2372, 2011.

96. Al-Fadhli R, Kelly SM, Tulandi T and Lin Tan S: Effects of different stages of endometriosis on the outcome of in vitro fertilization. J Obstet Gynaecol Can 28: 888-891, 2006.

97. Guo H, Wang Y, Chen Q, Chai W, Sun L, Ai A, Fu Y, Lyu Q and Kuang Y: Use of medroxyprogesterone acetate in women with ovarian endometriosis undergoing controlled ovarian hyperstimulation for in vitro fertilization. Sci Rep 7: 11927, 2017.

98. Alkudmani AB, Gat I, Buell D and Salman J: In vitro fertilization (IVF) success rates after surgically treated endometriosis and effect of time interval between surgery and IVF. J Minim Invasive Gynecol 25: 99-104, 2018.

99. González-Foruria I, Peñarrubia J, Borràs A, Manau D, Casals G, Peralta S, Creus M, Ferreri J, Vidal E, Carmona F, et al: Age, independent from ovarian reserve status, is the main prognostic factor in natural cycle in vitro fertilization. Fertil Steril 106: 342-347.e2, 2016.

100. Leonardi M, Papaleo E, Reschini M, Pagliardini L, Benaglia L, Candotti G, Viganó P, Quaranta L, Munaretto M, Candiani M, et al: Risk of miscarriage in women with endometriosis: Insights from in vitro fertilization cycles. Fertil Steril 106: 386-392.e3, 2016.

101. Coelho Neto MA, Martins Wde P, Luz MC, Jianini BT, Ferriani RA and Navarro PA: Endometriosis, ovarian reserve and live birth rate following in vitro fertilization. Rev Bras Ginecol Obstet 38: 218-224, 2016

102. Juneau C, Kraus E, Werner M, Franasiak J, Morin S, Patounakis G, Molinaro T, de Ziegler D and Scott RT: Patients with endometriosis have aneuploidy rates equivalent to their age-matched peers in the in vitro fertilization population. Fertil Steril 108: 284-288, 2017.

103. Boujenah J, Santulli P, Argent EM, Decanter C, Chauffour C and Poncelet P: First line management without IVF of infertility related to endometriosis: Result of medical therapy? Results of ovarian superovulation? Results of intrauterine insemination? CNGOF-HAS Endometriosis Guidelines. Gynécol Obstét Fertil Sénol 46: 331-337, 2018.

104. Wang W, Li R, Fang T, Huang L, Ouyang N, Wang L, Zhang Q and Yang D: Endometriosis fertility index score maybe more accurate for predicting the outcomes of in vitro fertilisation than r-AFS classification in women with endometriosis. Reprod Biol Endocrinol 11: 112, 2013.

105. Li X, Zeng C, Zhou YF, Yang HX, Shang J, Zhu SN and Xue Q: Endometriosis fertility index for predicting pregnancy after endometriosis surgery. Chin Med J (Engl) 130: 1932-1937, 2017.

106. Viardot-Foucault V, Tai BC, Chen ZJ, Lim GH, Loh SF, Tan HH, Nadarajah S and Chan JK: Estimating cumulative live-birth rates after IVF treatment with Kaplan-Meier and competing risk methods. Eur J Obstet Gynecol Reprod Biol 192: 41-46, 2015.

107. Coccia ME, Rizzello F, Mariani G, Bulletti C, Palagiano A and Scarselli G: Impact of endometriosis on in vitro fertilization and embryo transfer cycles in young women: A stage-dependent interference. Acta Obstet Gynecol Scand 90: 1232-1238, 2011.

108. Cohen J, Mounsambote L, Prier P, Argent EM, Selleret L, Chabbert-Buffet N, Delarouziere V, Levy R, Darai E and Antoine JM: Outcomes of first IVF/ICSI in young women with diminished ovarian reserve. Minerva Ginecol 69: 315-321, 2017.

109. Pallacks C, Hirchenhain J, Krüssel JS, Fehm TN and Fehr D: Endometriosis doubles odds for miscarriage in patients undergoing IVF or ICSI. Eur J Obstet Gynecol Reprod Biol 213: 33-38, 2017.

110. Polat M, Yarali I, Boynukalın K and Yarali H: In vitro fertilization for endometriosis-associated infertility. Wom Heal 11 633-641, 2015.

111. Rossi AC and Prefumo F: The effects of surgery for endometriosis on pregnancy outcomes following in vitro fertilization and embryo transfer: A systematic review and meta-analysis. Arch Gynecol Obstet 294: 647-655, 2016.

112. Senapati S, Sammel MD, Morse C and Barnhart KT: Impact of endometriosis on in vitro fertilization outcomes: An evaluation of the Society for Assisted Reproductive Technologies Database. Fertil Steril 106: 164-171.e1, 2016. 